\title{
The Influence of New Socio-Cultural Environment on Self-Esteem in Connection with Physique Traits in the Group of International Students in Russia
}

\author{
Varvara Yu. Bakholdina \\ Department of Anthropology \\ Lomonosov State University, Moscow \\ 119234, Leninskye gory, MSU 1, Moscow \\ Russian Federation \\ Alla A. Movsesian \\ Department of Anthropology \\ Lomonosov State University, Moscow \\ 119234, Leninskye gory, MSU 1, Moscow \\ Russian Federation
}

\begin{abstract}
The biopsychosocial approach in the anthropological investigations assumes that the associations of self-esteem with physique traits can presumably determine the level of psychological well-being, particularly in the new conditions of life in a foreign country. We analyzed associations of self-esteem with physique traits in a group of international students in Russia to reveal the peculiarities of these associations in the new sociocultural environment. The study group included 267 first-year students ( 79 females and 188 males), from 17 to 31 years of age. The results of the study confirm the data of other authors of higher self-esteem for males compared to females. Our investigation revealed gender differences in the associations of self-esteem with physique traits. Negative associations are more numerous and greater in absolute value in females, especially in the aspect of self-esteem of intellectual abilities. In males, negative associations with physique traits refer to self-esteem of appearance and other people's attitude. The results obtained reflect the concern of females about their abilities to cope with learning problems in unfamiliar conditions and in a foreign language environment. The similarity between males and females was observed in positive associations of self-esteem of health with physique traits.
\end{abstract}

Key words: physique traits, self-esteem, well-being, international students, gender differences

\section{Introduction}

In recent years, the biopsychosocial model has been widely discussed as the basis of an integrated approach, including the study of biological, psychological and social aspects of human nature, the interaction of which could largely determine the well-being and health (Frazier, 2020). This approach seems promising for revealing the problems, associated with the new life conditions of students, studying in a foreign country under the pressure of the new sociocultural, language and academic environment (Brisset, Safdar, Lewis \& Sabatier 2010; Ying \& Han 2006). In such case the level of self-esteem and correlations of self-esteem with physique traits can presumably determine the level of student' psychological well-being (Gattario, Frisén 2019; Mancuso 2016). We assume that the associations of different domains of self-esteem with physique traits could reflect the psychological well-being, connected with the pressure of the new sociocultural conditions. Our goal was to reveal and asses the peculiarities of such associations in a group of international students in Russia.

\section{Methods of Analysis}

The study group included 79 females who were 17 to 27 years of age (mean age of 20) and 188 males who were 17 to 31 years of age (mean age of 21). The sample consisted of first-year students from Asian and African countries. The following characteristics of physique were considered: height; body weight; body mass index (BMI); shoulder and pelvic width; chest diameters; chest, waist and hip girth; the waist-to-hip ratio (WHR). As generalized characteristics of physique, we used endomorphy, mesomorphy and ectomorphy scores, calculated according to Heath and Carter (Carter, Heath, 1990). In this study, we applied a technique of self-esteem evaluation proposed by T. Dembo and S. Rubinstein (Rubinstein 1970). 
According to this technique, several vertical scales that are each $100 \mathrm{~mm}$ long are presented to the subjects. Each of these scales represents a separate domain of self-esteem, and participants are asked to mark on it their level of selfesteem for a particular personal characteristic.

The distance from the lowest point of the vertical scale to the mark is regarded as a specified level of self-esteem. The advantage of this technique is in its ability to measure various domains of self-esteem, as well as an accurate quantitative presentation of the obtained data. Cronbach's alpha values for this method were 0.98 and 0.97 for male and female samples, respectively, that confirms the reliability of the test used. The study was approved by the Bioethics Committee of Moscow State University and performed on the basis of bioethics principles of the 1964 Helsinki declaration and its later amendments with informed written consent obtained from all participants, to whom the purpose of the research was explained. In the course of statistical data processing, we applied descriptive statistics and multiple regression analysis.

\section{Results}

Table 1 provides the data on specific domains of self-esteem for males and females. The results show that self-esteem is higher in males, with the exception of self-esteem related to health and other people's attitude, which are higher in females. In the female group, the minimum values do not fall below 13.0, while among males the minimum values are 5.0. The differences in self-esteem between males and females reach the threshold of statistical confidence $(p<0.05)$ for self-esteem of health, well-being and assessment of other people's attitude. To identify the associations between certain domains of self-esteem and physique traits, multiple regression analysis was performed. Table 2 shows the results of the analysis for males and females.

In the male sample, negative regression coefficients indicate inverse relationships between self-esteem of appearance and height and self-esteem of happiness and chest girth, waist girth, pelvic width and mesomorphy scores. Some domains of self-esteem in males reveal a negative correlation with absolute body size and muscle development. At the same time, regression coefficients indicate a positive correlation between self-esteem of health and the sagittal diameter of the chest, as well as between self-esteem of happiness and the ectomorphy score. The overall level of associations between self-esteem and physique traits in the male sample is not too high. In the female sample, in contrast to the males', twenty statistically significant partial regression coefficients are revealed, and seven of them (35.00\%) pertain to self-esteem of intelligence. All these coefficients, with the exception of ectomorphy scores, have a negative sign in the female sample, thus denoting an inverse relationship between self-esteem of intelligence and basic body sizes. The same direction of links, although indicated by a smaller number of significant regression coefficients, is revealed for self-esteem of well-being and other people's attitude. Positive associations were observed for physique traits and selfesteem of health, self-confidence and character.

\section{Discussion and Conclusion}

According to results obtained, most of the indicators of self-esteem are higher in males, confirming the results of other studies (Rentzsch, Wenzler, Schütz 2016; Zuckerman, Li, Hall 2016). However, significant indicators such as selfesteem of health, well-being and other people's attitude are higher among females, and the differences between males and females are statistically significant. The other people's attitude towards person is especially important due to the generally high significance of this domain of self-esteem in the person's self-concept (Baumeister, Leary, 1995; Brown, Sacco, 2017). Females' higher self-esteem for this indicator can be considered as an evidence of a higher level of psychological well-being. The results of multiple regression analysis allow investigating associations of self-esteem with physique traits. In the male sample, the expression of associations is low. Negative regression coefficients in males, revealed for physique traits and self-esteem of appearance, as well as self-esteem of other people's attitude and feeling happy, indicate the negative associations of self-esteem with large body size, as well as a preference for a slender physique. However, the regression coefficients between self-esteem of health and body sizes in males have positive signs. These associations can reflect the ideas about large body sizes as indicators of good health for men in some traditional ethnic communities. In the female sample, the level of associations between self-esteem and physique traits is much higher, confirming once again higher significance of these traits for females (Grossbard et al. 2009; Lowery et al. 2005). Among all domains of self-esteem, the most significant for females is self-esteem related to intelligence. The results obtained reflect the concern of girls about their abilities to cope with learning problems in unfamiliar conditions and in a foreign language environment. Psychological stress arising in connection with these factors is reflected in the negative associations of self-esteem and physique traits, manifested in statistically significant negative regression coefficients. Thus, self-esteem of intelligence in female sample was negatively associated with a large body mass and large girth size. 
In contrast, females with a pronounced ectomorphic component exhibit positive tendency in evaluating their own intelligence. We suppose that these results manifest two currently widespread gender stereotypes. One of them is associated with the ideas about intellectual superiority of males compared with females (Gálvez et al. 2019; Starr 2018).

The second stereotype connects the modern ideal of feminine beauty with slimness and thinness. Our results confirm that both stereotypes, accepted by females themselves, create additional stress in the female sample and hinder their successful adaptation to new environmental conditions. A similar pattern of associations with physique traits is observed for self-esteem of well-being and other people's attitude. The positive associations of self-esteem of character and health with physique traits could reflect an effect of traditional ideas about female appearance in the countries, where the students came from. The female features of the physique, such as natural fullness, in these countries may be associated with beauty and health and considered attractive. Possibly, a positive attitude towards their own appearance can play a compensatory role and contribute to the successful adaptation of females to new living conditions, despite the stress associated with their studies. The similarity between males and females is observed in positive associations of physique traits with the assessment of the health, which may reflect common ideas about healthy physique in the traditional communities. In the future, it would be interesting to conduct similar research for senior international students since it could be assumed that the level of self-esteem among males and females will be higher in senior courses.

Table 1. Mean values (M), standard deviations (SD), variation range (Min-Max) and statistical significance $(p)$ of differences between females and males in self-esteem indicators by $t$-test.

\begin{tabular}{|c|c|c|c|c|c|c|c|}
\hline & $\begin{array}{l}\text { Females } \\
\mathrm{N}=79\end{array}$ & $\begin{array}{l}\text { Males } \\
\mathrm{N}=188\end{array}$ & & Femal & & Males & \\
\hline $\begin{array}{l}\text { Self- } \\
\text { esteem } \\
\text { indicators }\end{array}$ & $\begin{array}{l}\mathrm{M} \\
\text { (SD) }\end{array}$ & $\begin{array}{l}\mathrm{M} \\
\text { (SD) }\end{array}$ & $p$ & Min & Max & Min & Max \\
\hline Health & $\begin{array}{l}81.77 \\
(15.99)\end{array}$ & $\begin{array}{l}73.45 \\
(15.50)\end{array}$ & 0.011 & 19.00 & 100.00 & 19.00 & 100.00 \\
\hline Well-being & $\begin{array}{l}74.08 \\
(23.56)\end{array}$ & $\begin{array}{l}84.34 \\
(22.51)\end{array}$ & 0.002 & 13.00 & 100.00 & 5.00 & 100.00 \\
\hline $\begin{array}{l}\text { Self- } \\
\text { confidence }\end{array}$ & $\begin{array}{l}80.47 \\
(17.73)\end{array}$ & $\begin{array}{l}85.07 \\
(18.34)\end{array}$ & 0.113 & 35.00 & 100.00 & 5.00 & 100.00 \\
\hline $\begin{array}{l}\text { Other } \\
\text { people's } \\
\text { attitude }\end{array}$ & $\begin{array}{l}83.83 \\
(17.87)\end{array}$ & $\begin{array}{l}78.34 \\
(18.48)\end{array}$ & 0.022 & 30.00 & 100.00 & 15.00 & 100.00 \\
\hline Appearance & $\begin{array}{l}78.69 \\
(14.63)\end{array}$ & $\begin{array}{l}80.31 \\
(18.06)\end{array}$ & 0.558 & 28.00 & 100.00 & 10.00 & 100.00 \\
\hline Intelligence & $\begin{array}{l}79.62 \\
(15.64)\end{array}$ & $\begin{array}{l}82.66 \\
(16.89)\end{array}$ & 0.279 & 28.00 & 100.00 & 18.00 & 100.00 \\
\hline Character & $\begin{array}{l}80.89 \\
(19.96)\end{array}$ & $\begin{array}{l}80.95 \\
(18.70)\end{array}$ & 0.980 & 45.00 & 100.00 & 17.00 & 100.00 \\
\hline Happiness & $\begin{array}{l}79.62 \\
(20.54)\end{array}$ & $\begin{array}{l}82.12 \\
(21.72)\end{array}$ & 0.491 & 53.38 & 99.375 & 31.37 & 100.00 \\
\hline
\end{tabular}


Table 2. Partial coefficients of multiple regression $\beta$ for self-esteem indicators (1-8) and physique traits

\begin{tabular}{lllllllll}
\hline \multicolumn{7}{l}{ Males } & & \\
\hline \multicolumn{7}{l}{ Self-esteem indicators } \\
\hline Physique traits & 1 & 2 & 3 & 4 & 5 & 6 & 7 & 8 \\
\hline Height & - & - & - & - & -0.40 & - & - & - \\
Sagittal chest diameter & 0.56 & - & - & - & - & - & - & - \\
Waist girth & - & - & - & - & - & - & - & -0.60 \\
Thigh girth & 0.53 & - & - & - & - & - & - & - \\
Calf girth & - & - & - & - & -0.43 & - & - & - \\
Elbow width & - & - & - & -0.54 & - & - & - & - \\
Wrist width & - & - & - & -0.57 & - & - & - & - \\
Knee width & 0.49 & - & - & - & - & - & - & - \\
Mesomorphy score & - & - & - & - & - & - & - & 0.58 \\
Ectomorphy score & - & - & - & - & - & - & - & 0.58 \\
\hline
\end{tabular}

\section{Females}

\section{Self-esteem indicators}

\begin{tabular}{lllllllll}
\hline Physique traits & 1 & 2 & 3 & 4 & 5 & 6 & 7 & 8 \\
\hline Body weight & - & - & - & - & - & -2.68 & - & - \\
Pelvic width & 0.95 & $-1.26^{*}$ & 0.83 & - & - & -1.73 & - & - \\
Transversal chest diameter & - & - & - & - & - & -2.39 & 1.98 & - \\
Chest girth & - & - & - & - & - & -2.47 & 1.70 & - \\
Hip girth & $1.08^{*}$ & -0.81 & 1.19 & -1.06 & 0.69 & $-2.76^{*}$ & 1.41 & 0.80 \\
Upper arm girth & - & -0.78 & - & - & 0.83 & $-2.49^{*}$ & $1.79 *$ & - \\
Forearm girth & - & - & - & - & - & -1.77 & - & - \\
Thigh girth & - & - & - & - & - & -2.67 & - & - \\
Mesomorphy score & - & - & - & - & 0.75 & - & - & - \\
Ectomorphy score & - & - & - & - & -0.84 & 1.86 & -1.45 & - \\
\hline
\end{tabular}

Note. Designations of different domains of self-esteem: 1 - health; 2 - well-being; 3 - self-confidence; 4 -other people's attitude; 5 - appearance; 6 - intelligence; 7 - character; 8 - happiness. ${ }^{*} \mathrm{p}<0.05$.

\section{Acknowledgments}

This study was supported by the Russian Foundation for Basic Researches (Grant number: RFBR No 19-09-00318).

\section{References}

Baumeister, R., Leary M.R. (1995). The need to belong: desire for interpersonal attachments as a fundamental human motivation. Psychological Bulletin, 117, 497-529. https://doi.org/10.1037/0033-2909.117.3.497 
Brisset, C., Safdar S., Lewis J.R. \& Sabatier, C. (2010). Psychological and sociocultural adaptation of university students in France: The case of Vietnamese international students. International Journal of Intercultural Relations, 34, 413-426. doi:10.1016/j.ijintrel.2010.02.009

Brown, M., Sacco, D.F. (2017). Greater need to belong predicts a stronger preference for extraverted faces. Personality and Individual Differences, 104, 220-223. 10.1016/j.paid.2016.08.012

Carter, J.L., Heath, B.H. (1990). Somatotyping - development and applications. Cambridge: Cambridge University Press. DOI: https://trove.nla.gov.au/work/6271128.

Frazier, L.D. (2020). The past, present, and future of the biopsychosocial model: A review of The Biopsychosocial Model of Health and Disease: New philosophical and scientific developments by Derek Bolton and Grant Gillett. New Ideas in Psychology, 57, 100755, 1-3. https://doi.org/10.1016/j.newideapsych.2019.100755

Galves, R.H., Tiffenberg, V. \& Altszyler E. (2019). Half a Century of Stereotyping Associations Between Gender and Intellectual Ability in Films. Sex Roles: A Journal of Research, 81(9-10), 643-654. DOI: $10.2139 / \mathrm{ssrn} .3110865$.

Gattario, K.H., Frisén, A. (2019). From negative to positive body image: Men's and women's journeys from early adolescence to emerging adulthood. Body Image, 28, 53-65. https://doi.org/10.1016/j.bodyim.2018.12.002.

Grossbard, J.R., Lee, C.M., Neighbors, C., Larimer, M.E. (2009). Body image concerns and contingent self-esteem in male and female college students. Sex Roles: A Journal of Research, 60, 198-207. http://dx.doi.org/10.1007/s11199-008-9535-y.

Lowery, S., Kurpius, S., Befort, C., Blanks, E.H., Sollenberger, S., Nicpon, M.F., Huser, L. (2005). Body Image, SelfEsteem, and Health-Related Behaviors among Male and Female First Year College Students. Journal of College Student Development, 46, 612-623. https://doi.org/10.1353/csd.2005.0062.

Mancuso, S.G. (2016). Body image inflexibility mediates the relationship between body image evaluation and maladaptive body image coping strategies. Body Image, 16, 28-31. https://doi.org/10.1016/j.bodyim.2015.10.003.

Rentzsch, K., Wenzler, M.P., Schütz, A. (2016). The structure of multidimensional self-esteem across age and gender. Personality and Individual Differences, 88, 139-147. http://dx.doi.org/10.1016/j.paid.2015.09.012.

Rubinstein, S.Y. (1970). Experimental methods of pathopsychology and experience of their application in the clinic. Moscow, Medicine (in Russian).

Starr, C.R. (2018). "I'm Not a Science Nerd!" STEM Stereotypes, Identity, and Motivation among Undergraduate Women. Psychology of Women Quarterly, 42(4), 489-503. https://doi.org/10.1177/0361684318793848.

Ying, Y-W \& Han, M. (2006). The contribution of personality, acculturative stressors, and social affiliation to adjustment: A longitudinal study of Taiwanese students in the United States. International Journal of Intercultural Relations, 30, 623-635. DOI: 10.1016/j.ijintrel.2006.02.001.

Zuckerman, M., Li, C., Hall, J.A. (2016). When men and women differ in self-esteem and when they don't: A metaanalysis. Journal of Research in Personality, 64, 34-51. http://dx.doi.org/10.1016/j.jrp.2016.07.007. 